\title{
Fast and Efficient Neural Conversion of Human Hematopoietic Cells
}

\author{
Julio Castaño, ${ }^{1,9}$ Pablo Menendez, ${ }^{1,2,9}$ Cristina Bruzos-Cidon, ${ }^{3,9}$ Marco Straccia, ${ }^{4,5}$ Amaia Sousa, ${ }^{6}$ \\ Lorea Zabaleta, ${ }^{7}$ Nerea Vazquez, ${ }^{6}$ Amaia Zubiarrain, ${ }^{6,7}$ Kai-Christian Sonntag, ${ }^{8}$ Luisa Ugedo, ${ }^{3}$ \\ Xonia Carvajal-Vergara, ${ }^{7,10}$ Josep Maria Canals, ${ }^{4,5}$ Maria Torrecilla, ${ }^{3}$ Rosario Sanchez-Pernaute, ${ }^{6, *}$ \\ and Alessandra Giorgetti ${ }^{1, *}$ \\ ${ }^{1}$ Josep Carreras Leukemia Research Institute, Cell Therapy Program of the University of Barcelona, Barcelona 08036, Spain \\ 2Institució Catalana de Recerca i Estudis Avançats (ICREA), Barcelona 08010, Spain \\ ${ }^{3}$ Department of Pharmacology, Faculty of Medicine and Dentistry, University of the Basque Country (UPV/EHU), Leioa 48940, Spain \\ ${ }^{4}$ Department of Cell Biology, Immunology and Neurosciences, Faculty of Medicine, Institut d'Investigacions Biomèdiques August Pi i Sunyer (IDIBAPS), \\ University of Barcelona, Barcelona 08036, Spain \\ ${ }^{5}$ Centro de Investigaciones Biomédicas en Red sobre Enfermedades Neurodegenerativas (CIBERNED), Barcelona 08036, Spain \\ ${ }^{6}$ Laboratory of Stem Cells and Neural Repair, Inbiomed, San Sebastian 20009, Spain \\ ${ }^{7}$ Cell Reprogramming and Differentiation Platform, Inbiomed, San Sebastian 20009, Spain \\ ${ }^{8}$ Department of Psychiatry, McLean Hospital, Harvard Medical School, Belmont, MA 02478, USA \\ ${ }^{9}$ Co-first author \\ ${ }^{10}$ Present address: Department of Cell Therapy, Centro de Investigación Médica Aplicada (CIMA), Pamplona 31008, Spain \\ *Correspondence: rpernaute@inbiomed.org (R.S.-P.), agiorgetti@carrerasresearch.org (A.G.) \\ http://dx.doi.org/10.1016/j.stemcr.2014.10.008 \\ This is an open access article under the CC BY-NC-ND license (http://creativecommons.org/licenses/by-nc-nd/3.0/).
}

\section{SUMMARY}

Neurons obtained directly from human somatic cells hold great promise for disease modeling and drug screening. Available protocols rely on overexpression of transcription factors using integrative vectors and are often slow, complex, and inefficient. We report a fast and efficient approach for generating induced neural cells (iNCs) directly from human hematopoietic cells using Sendai virus. Upon SOX2 and $c-M Y C$ expression, CD133-positive cord blood cells rapidly adopt a neuroepithelial morphology and exhibit high expansion capacity. Under defined neurogenic culture conditions, they express mature neuronal markers and fire spontaneous action potentials that can be modulated with neurotransmitters. SOX2 and c-MYC are also sufficient to convert peripheral blood mononuclear cells into iNCs. However, the conversion process is less efficient and resulting iNCs have limited expansion capacity and electrophysiological activity upon differentiation. Our study demonstrates rapid and efficient generation of iNCs from hematopoietic cells while underscoring the impact of target cells on conversion efficiency.

\section{INTRODUCTION}

Cellular reprogramming has opened new avenues to investigate human disease and identify potential targets for drug discovery (Bellin et al., 2012). This technology is particularly useful for cell types in which the target tissue is not accessible, like the brain. It is now possible to differentiate human embryonic stem (hES) and human-induced pluripotent stem (hiPS) cells into different types of neurons (Hu et al., 2010; Qiang et al., 2014; Velasco et al., 2014; Zhang et al., 2013). However, the generation of neuronal cells from pluripotent stem cells involves long and complex protocols with problematic variability. Alternatively, direct lineage conversion (or transdifferentiation) of somatic cells into neurons (induced neurons [iNs]) has been achieved by forced expression of lineage-specific transcription factors and microRNAs (miRNA) (Ambasudhan et al., 2011; Caiazzo et al., 2011; Pang et al., 2011; Pfisterer et al., 2011; Vierbuchen et al., 2010; Yoo et al., 2011). Using this approach, several cell types (Giorgetti et al., 2012; Karow et al., 2012; Marro et al., 2011) have been converted into functional neurons in vitro and also in vivo (Guo et al., 2014; Su et al., 2014; Torper et al., 2013). However, for de- livery of exogenous reprogramming factors, most available protocols have used integrative viral vectors, and the conversion process was rather inefficient. Only recently, nonintegrative methods based on Sendai virus (SeV) or chemically defined culture conditions have been described for the direct conversion of nonhuman cells into neural progenitor cells (iNPCs) (Cheng et al., 2014; Lu et al., 2013).

Here, we investigated whether a similar nonintegrative strategy is applicable for the conversion of human hematopoietic cells directly into neurons. Importantly, peripheral blood (PB), which is routinely used in medical diagnoses, represents a noninvasive and easily accessible source of cells for reprogramming both healthy donor and diseasespecific patient cells. Based on our previous study (Giorgetti et al., 2012), we chose SOX2 and c-MYC SeV vectors to reprogram CD133-positive cord blood (CB) cells and adult PB mononuclear cells (PB-MNCs). We found that the overexpression of SOX2 and $c-M Y C$ by $\mathrm{SeV}$ accelerated and increased the efficiency of neural conversion of CD133positive $\mathrm{CB}$ cells (CB-iNCs) when compared with retroviral vectors. SOX2 and $c-M Y C$ were also sufficient to convert PB-MNCs into neuronal-like cells (PB-iNCs). However, compared with CB-iNCs, the process was less efficient, 
and the resulting PB-iNCs showed limited expansion, differentiation capacity, and functional properties. Our results demonstrate the feasibility for rapid and efficient generation of iNCs from CD133-positive CB cells using nonintegrative $\mathrm{SeV}$ while underscoring the impact of target cell developmental stage on the reprogramming process for lineage conversion.

\section{RESULTS}

Rapid and Efficient Generation of iNCs from CD133-Positive CB Cells

We first tested whether the forced expression of SOX2 and $c-M Y C$ by $\mathrm{SeV}$ can induce the conversion of CD133positive CB cells directly into neural cells (iNCs); 50,000 magnetic activated cell sorting-isolated CD133-positive $\mathrm{CB}$ cells (purity $>95 \%$; data not shown) were infected at a low multiplicity of infection (MOI) $(<5 \mathrm{MOI}$, infection efficiency $80 \%-85 \%$; data not shown) and cocultured on irradiated rat primary astrocytes in the presence of $\mathrm{N} 2$ medium containing bone morphogenetic protein (BMP), transforming growth factor $\beta$ (TGF- $\beta$ ), and glycogen synthase kinase$3 \beta$ (GSK-3 $\beta$ ) inhibitors (Ladewig et al., 2012) (Figure 1A). Overexpression of $\mathrm{SOX} 2$ and $c-M Y C$ by $\mathrm{SeV}$ rapidly induced the acquisition of neuroepithelial morphology in CD133positive CB cells (Figure 1Ba-c). After removal of inhibitors (day 10), reprogrammed cells showed a high expansion capacity, acquired an immature neural morphology (day 15; Figure $1 \mathrm{Bd}$ ), and progressively formed a neural network. By day 30, CB-iNCs displayed a more complex cytoarchitecture with long processes and elaborated branching, preferentially organized into clusters, with persistence of proliferating cores (Figure 1Be).

Immunostaining showed that by day 15 most cells were positive for SOX2, and some of them already expressed beta-III tubulin (TUJ1) (Figure 1Ca). By day 30, the cells were organized in clusters that expressed TUJ1 and were interconnected by microtubule-associated protein 2 (MAP2)-positive fibers (Figure $1 \mathrm{Cb}-\mathrm{d}$ ); there were some PAX6-positive cells within the clusters (indicated by white arrows; Figure 1Cc). Quantitative analysis revealed that after 30 days of neural induction a majority of HUNU cells were positive for TUJ1 ( $~ 80 \%, \mathrm{n}[\mathrm{HUNU}$ cells] = 17,330; two independent experiments) (Figures S1A and S1B available online) and around 50\% (n[HUNU cells] $=24,362$ ) were positive for MAP2 (Figure S1C). Moreover, fluorescence-activated cell sorting (FACS) analysis revealed that over $25 \%$ of cells were neural cell adhesion molecule (N-CAM)-positive after 15 days of induction ( 20 million $\mathrm{N}$-CAM-positive cells at day 15; Figures $1 \mathrm{D}$ and $1 \mathrm{E}$ ), and the proportion of N-CAM-positive cells progressively increased over time ( $\sim 60$ million at day 45 , Figures $1 \mathrm{D}$ and 1E). On the other hand, the loss of CD45, a hematopoietic specific antigen, along with the downregulation of $\beta 2$-microglobulin (B2M) indicated that reprogrammed cells had lost their hematopoietic identity (Figures 1D and S1D). Importantly, the emergence of CB-iNCs was accompanied by activation of endogenous SOX2 (82-fold at day 10; Figure $1 \mathrm{~F}$ ), whereas expression of other pluripotency-related genes such as OCT4, NANOG, CRIPTO, REX1, and DNMT3B (Figure $1 \mathrm{G}$ ), as well as endodermal/mesodermal-specific transcription factors (GATA4 and BRACHYURY; data not shown), was never detected throughout the conversion process. Likewise, analysis of TRA-1-60 at different time points by FACS analysis showed no positive cells during the conversion process (Figure S1E). These results were consistent in five independent experiments (i.e., five CB units), demonstrating the reproducibility of this reprogramming strategy.

A more extensive quantitative RT-PCR (qRT-PCR) analysis of CB-iNCs confirmed a remarkable upregulation of TUI1, doublecortin $(D C X)$, and MAP2 already at 15 days after neural induction, whereas PAX6 and early neural markers (MUSASHI, SOX1, and NESTIN) were present at lower levels (Figure 2A). While recent work identified MASH1 as the most important driver of neural conversion in fibroblasts (Chanda et al., 2014), we observed only marginal induction of MASH1 expression in CB-iNCs (Figure $2 \mathrm{~A}$ ). In contrast, $B R N 2$ was progressively activated in CB-iNCs during the neural conversion (Figure 2A), suggesting an involvement of BRN2 in this process, in line with other recent reports (Lujan et al., 2012; Zou et al., 2014).

At this stage, there was little or no expression of mature postmitotic neuronal markers such as NEUN (RBFOX-3), vesicularglutamate transporter 1 ( $v G L U T 1 / S L C 17 A 7)$, and TAU (MAPT) (Figure 2A). CB-iNCs maintained this molecular profile during their propagation (days 15 to 45), when the cells were cultured in the presence of $\mathrm{N} 2+\mathrm{B} 27$ with fibroblast growth factor 2 (FGF2) and brain-derived neurotrophic factor (BDNF). These data suggest that the conversion process rapidly activates a transcriptional profile characteristic of committed neuroblasts and early neural progenitors.

\section{CB-iNCs Are Expandable and Differentiate into}

Functional Neurons In Vitro

To confirm the presence of an expandable neural progenitor population, CB-iNCs were disaggregated as single cells and were seeded on matrigel in the presence of N2 media containing FGF2. Under these culture conditions, CB-iNCs displayed neuroepithelial morphology within 1 week (Figure $2 \mathrm{Ba}$ ) and expressed the early neural marker NESTIN (Figure 2Bb). qRT-PCR analysis also showed upregulation of mRNA levels of early neural progenitor markers (NESTIN, MUSASHI, and SOX1) and concomitant downregulation of neural committed markers (PAX6, TUJ1, DCX, 
A

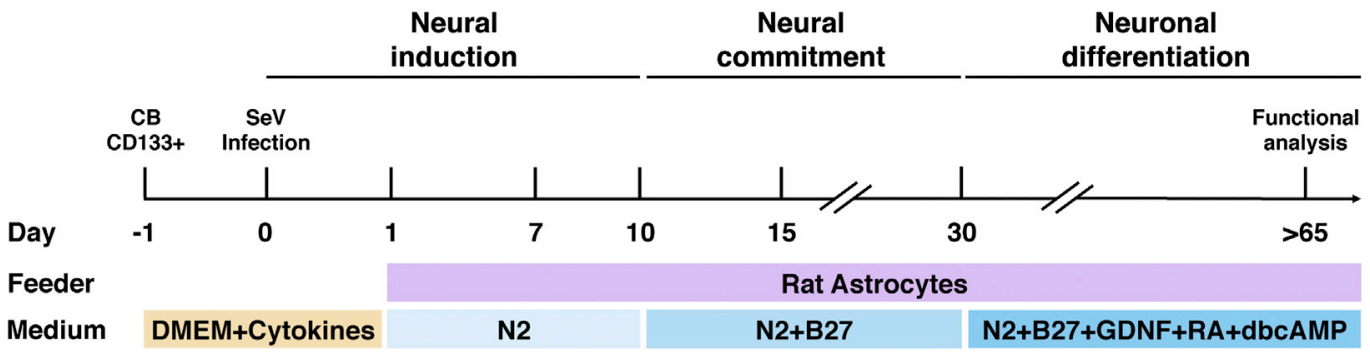

B

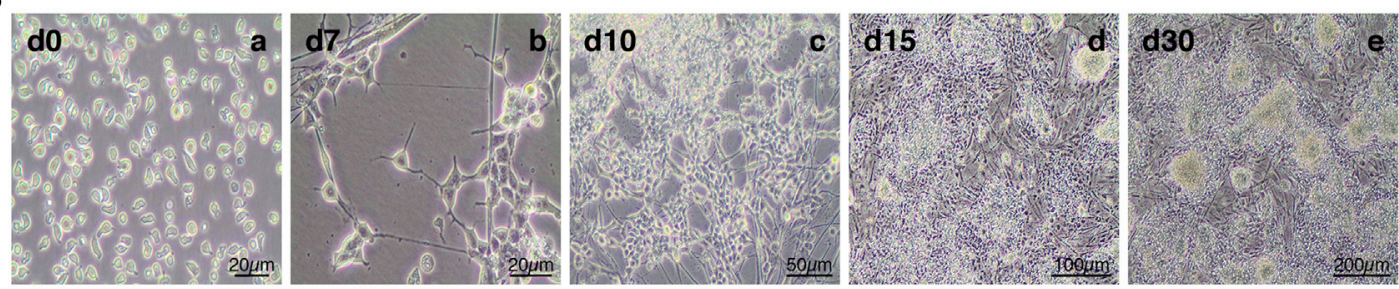

C

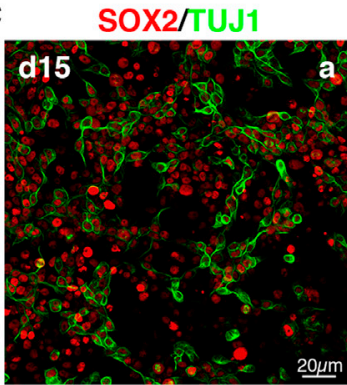

HUNU/TUJ1

SOX2/TUJ1/PAX6
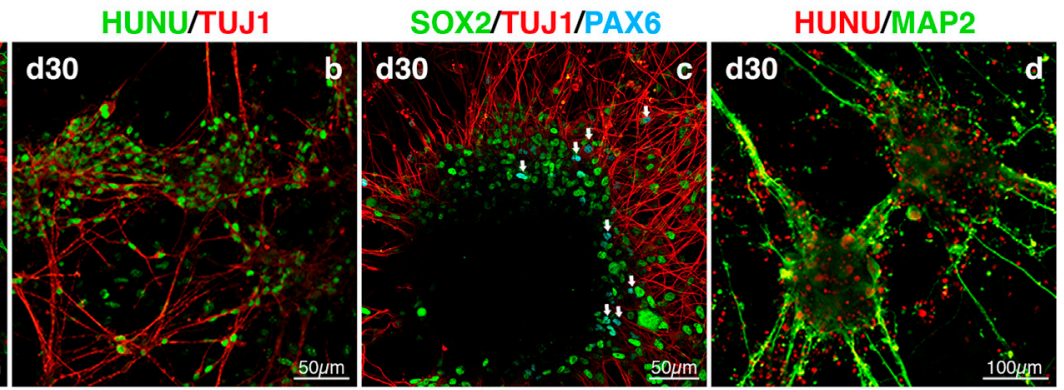

D
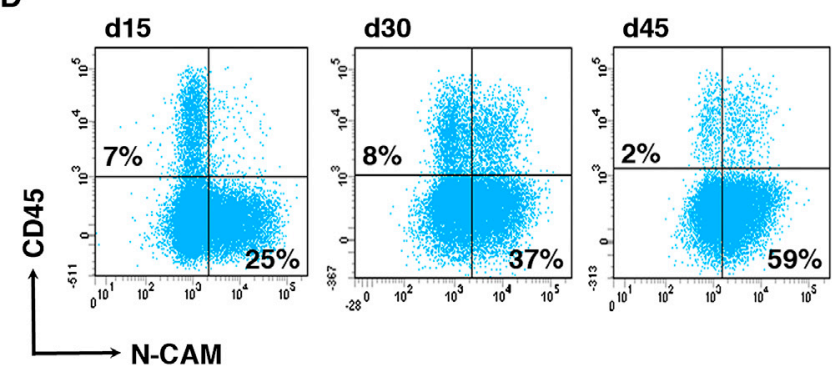

E

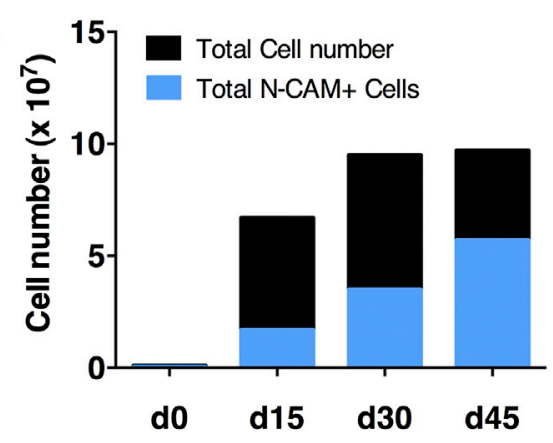

$\mathbf{F}$

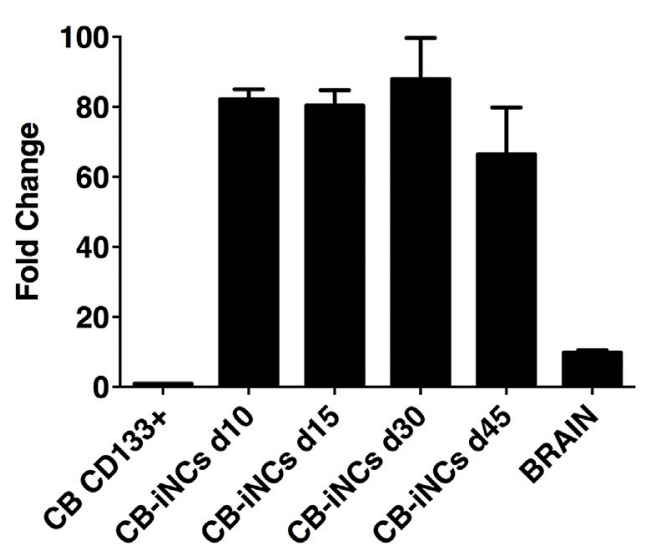

G

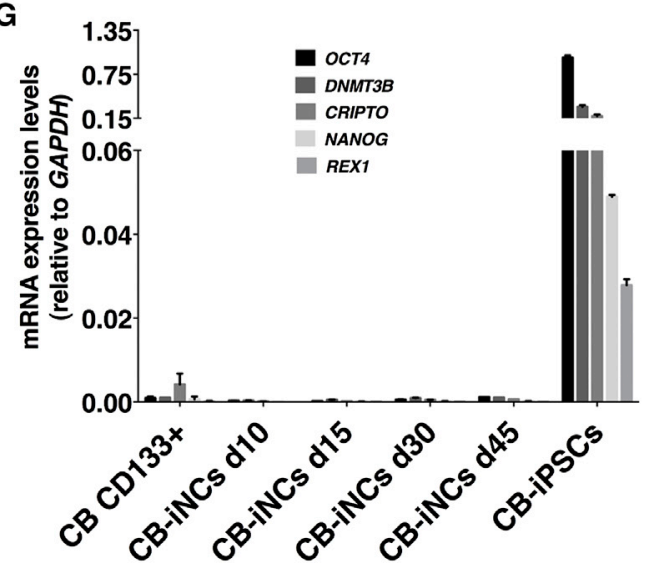

(legend on next page) 
and MAP2) (Figure 2C). Importantly, these expandable CBiNCs could be frozen and thawed and propagated in culture for $>60$ passages while maintaining their neural phenotype and chromosomal stability (Figures S2A and S2B). These data strongly suggest that overexpression of SOX2 and c$M Y C$ combined with permissive culture conditions drives the direct conversion of CD133-positive CB cells into a heterogeneous neural cell population reminiscent of adult neural stem cells present in neurogenic niches (Codega et al., 2014). Long-term propagated CB-iNCs showed persistent expression of $\mathrm{SeV}$, which was completely eliminated only after temperature treatment (Figure 2D).

We next assessed the differentiation potential of CBiNCs. For this purpose, they were dissociated into single cells and replated on irradiated rat astrocytes in the presence of neural differentiation medium (Figure 1A). After 35 days under differentiation conditions, CB-iNCs displayed extensive arborization (Figure 3Aa) and expressed axonal neurofilament SMI 312 (NF) (Figure 3Ab). Moreover, TAU-positive neurons showed appropriate downregulation of SOX2 nuclear expression, and MAP2/TAU segregation was observed into different subcellular compartments (dendrites and axons, respectively; Figure 3Ac and d). Some cells also expressed NEUN (RBFOX-3), indicative of postmitotic mature neurons (Figure $3 \mathrm{Ae}$ ). In these culture conditions, about $17 \%$ of cells ( $\mathrm{n}$ [cells] $=409$ ) were found to be immunopositive for gamma-aminobutyric acid (GABA) (Figure 3Ae) and 47\% (n[cells] = 1442) for vGLUT1 (Figure $3 \mathrm{Af}$ ). Finally, mature CB-iNCs expressed synaptic proteins as indicated by the expression of Synapsin1 (SYN) and Synaptic vesicle protein 2 (SV2) (Figure 3Ag-i). Other markers corresponding to monoamine transmitter pheno- types such as tyrosine hydroxylase (for dopamine and noradrenergic neurons) and serotonin were not expressed (data not shown). Nonetheless, we cannot exclude that CB-iNCs upon more specific condition culture could differentiate into other neuronal phenotypes. Likewise, under these conditions, astrocytic and oligodendrocitic markers were not detected, but glial fibrillary acidic protein (GFAP)-positive cells could be generated when cultured in the presence of epidermal growth factor and fetal bovine serum (data not shown).

We next examined the electrophysiological properties of CB-iNCs using whole-cell recordings. Mature neurons were visualized by transduction with the SYN::GFP reporter. Both inward $\mathrm{Na}^{+}$and outward $\mathrm{K}^{+}$voltage-dependent currents were reliably evoked by depolarizing voltage steps from a holding potential of $-50 \mathrm{mV}$ (data not shown; Figures S3A and S3B). Single or multiple action potentials were triggered by injection of depolarizing current steps in 15 of 37 cells (Figures 3B and 3C). Moreover, 60\% of these active cells (9 of 15 cells) showed spontaneous action potentials (Figure 3B). Firing rate was increased upon glutamate application $(100 \mu \mathrm{M})$ and completely inhibited when $\alpha$-amino3-hydroxy-5-methyl-4-isoxazolepropionic acid (AMPA) and N-methyl-D-aspartate (NMDA) glutamate receptor antagonists were simultaneously perfused (50 $\mu \mathrm{M}$ DNQX and $50 \mu \mathrm{M}$ MK801) (Figure 3C). In another experiment (Figure S3C), bath perfusion of glutamate $(200 \mu \mathrm{M})$ induced an inward current of $37.53 \pm 13 \mathrm{pA}(\mathrm{n}=5$ of 9$)$ that was completely reversed by the AMPA receptor antagonist DNQX $(50 \mu \mathrm{M})$. Consistently, immunostaining of recorded cells showed expression of vGLUT1 (Figure 3C). Furthermore, in some cells, the spontaneous firing rate

Figure 1. Generation of iNCs from CD133-Positive CB Cells Using SeV Vectors

(A) Schematic timeline of neural conversion. CD133-positive CB cells transduced with SOX2 and C-MYC SeV vectors were seeded on irradiated rat astrocytes and cultured with N2 medium supplemented with LDN, CHIR99021, and SB431542 compounds for 10 days. From days 10 to 30 , cells were cultured in $\mathrm{N} 2+\mathrm{B} 27$ medium. From day 30 onward, CB-iNCs were terminally differentiated in the presence of $\mathrm{N} 2+\mathrm{B} 27$ medium with BDNF, GDNF, RA, and dbcAMP. Electrophysiology was performed at day 65 .

(B) Representative phase-contrast images illustrating the morphological conversion of CD133-positive CB cells into iNCs. Note that cells with neural progenitor morphology were identifiable already at day $7(n=5$ independent experiments). Scale bars are as indicated in the panels.

(C) Representative immunofluorescence images of CB-iNCs at days 15 and 30. Two weeks after induction, CB-iNCs were S0X2 positive and TUJ1 positive and exhibited a neural morphology (a). By day 30, CB-iNCs showed a more complex cytoarchitecture, organized in clusters with long TUJ1- and MAP2-positive processes (b-d). Of note, few PAX6-positive cells (white arrows) were observed (c). Scale bars are as indicated in the panels.

(D) Flow cytometry quantification of CD45 and CD56 (N-CAM) in a representative experiment, showing the progressive increase in N-CAMpositive cells reaching $\sim 60 \%$ by day 45 .

(E) Quantification of total cell number and N-CAM-positive neuronal cells at differentiation days 15, 30, and 45.

(F) Quantification of endogenous SOX2 mRNA levels in CB-iNCs by qRT-PCR analysis. Data are shown as fold induction of SOX2 mRNA level in CB-iNCs relative to CD133-positive CB cells, which is considered as 1. Human total brain RNA (YORBIO) was used as positive control. Data are represented as mean $\pm S D(n=3$ independent experiments).

(G) Pluripotency genes (OCT4, NANOG, REX1, CRIPTO, and DNMT3B) expression was not detected in CB-iNCs by qRT-PCR during the conversion process. CB derived iPSCs were used as positive control. Data are represented as mean $\pm S D$ ( $n=3$ independent experiments). See also Figure S1. 
A

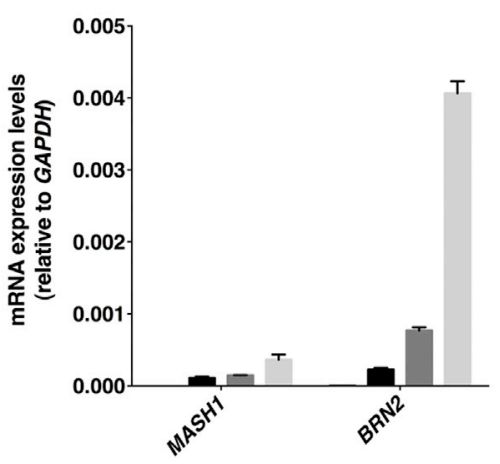

Neural progenitor markers

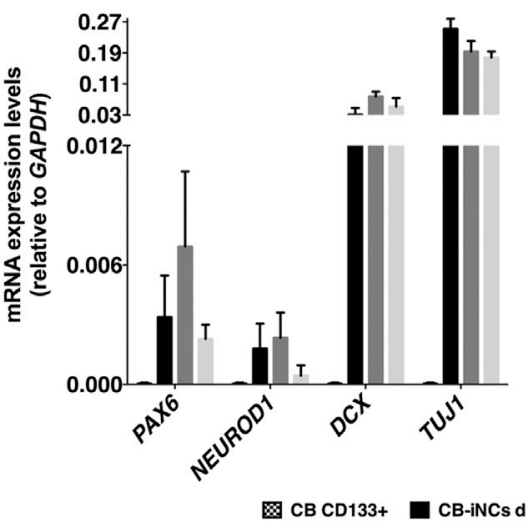

圆 $\mathrm{CB} C D 133+$

B

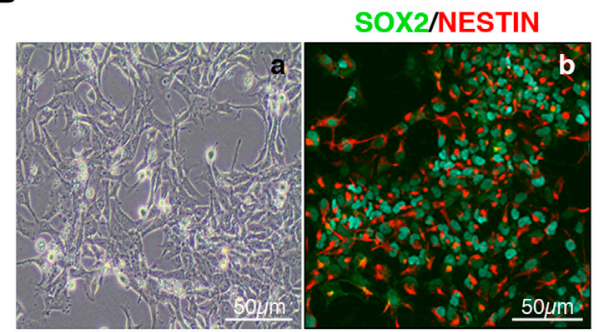

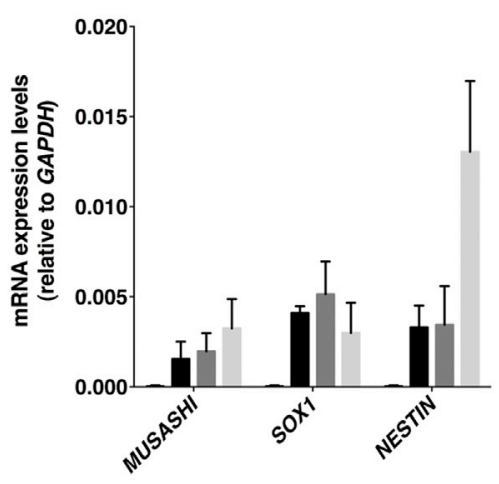

Mature neuronal markers

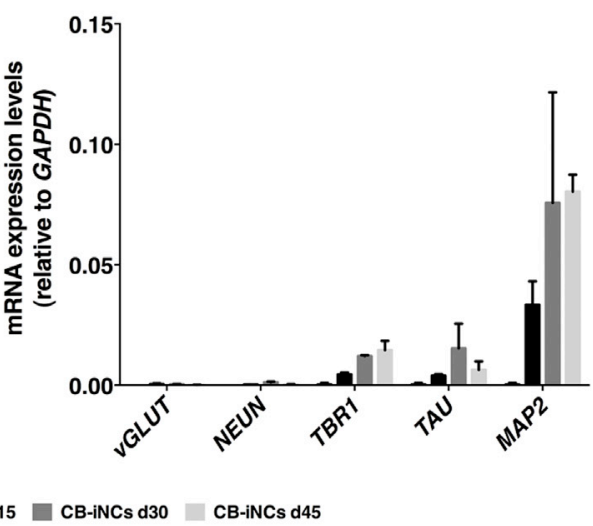

C

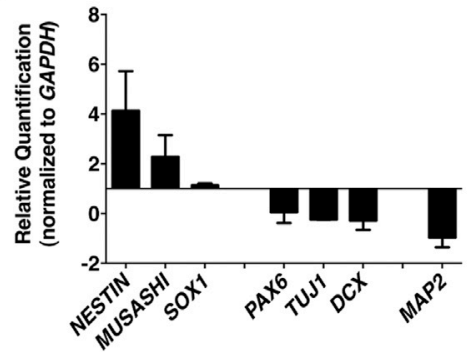

Figure 2. Characterization iNCs Derived from CD133-Positive CB Cells

(A) Quantification of expression levels by qRT-PCR of a panel of early, immature, and mature neuronal markers in CD133-positive CB cells and CB-iNCs at 15, 30, and 45 days of neural induction and propagation. Data are represented as mean \pm SD $(n=3$ independent experiments). Expression of these genes was not detected in untransduced CD133-positive CB cells.

(B) Representative phase-contrast live image (a) and immunostaining (b) of CB-iNCs at passage 5 cultured on matrigel in the presence of FGF2. CB-iNCs acquired a neural epithelial-like morphology and expressed early neural progenitor markers such as NESTIN and SOX2. The scale bar is as indicated in the panels.

(C) qRT-PCR analysis showing transcriptional changes in the CB-iNCs propagated on matrigel in the presence of FGF2 for five passages relative to CB-iNCs at day 30 of neural induction. Data are represented as mean \pm SD ( $n=3$ independent experiments).

(D) SeV vectors analyzed by qRT-PCR after 20 passages before and after temperature treatment $\left(39^{\circ} \mathrm{C}\right)$-mediated silencing. Data are represented as mean \pm SD $(n=3$ independent experiments).

See also Figure S2.
D

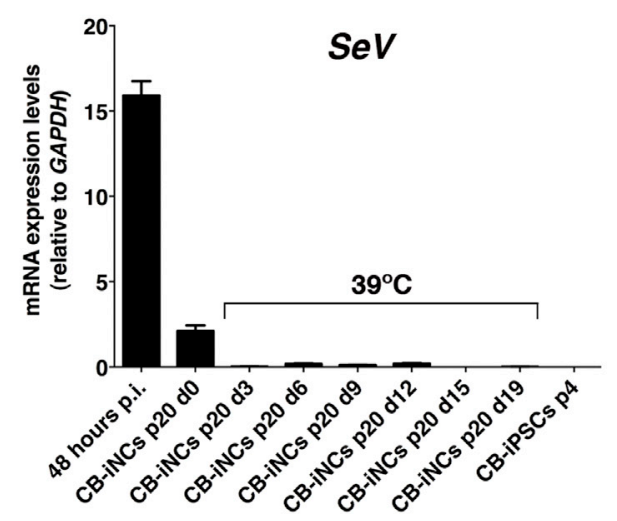


was completely suppressed upon GABA application (Figure S3D). There were significant differences in the intrinsic electrophysiological properties-membrane capacitance, membrane resistance, and resting membrane potentialbetween the spontaneously active and nonactive cells (Figure 3D). Indeed, in the spontaneously active cells, the membrane capacitance was larger and the resting membrane potentials less depolarized than those recorded from nonactive cells, suggesting that spontaneously active cells were more mature (Johnson et al., 2007). Importantly, CB-iNCs frozen and thawed could also be differentiated into mature neurons that displayed spontaneous electrical activity (Figure S3E). Taken together, our data show that CB-iNCs generated by expression of SOX2 and $c-M Y C \mathrm{SeV}$ are expandable and have the potential to differentiate in vitro into electrophysiological active cells.

iNCs Generated from PB-MNCs Displayed Low Expansion Capacity and Limited Electrophysiological Activity

PB would be a highly amenable source for reprogramming patient-specific cells. Thus, we next investigated the possibility of converting PB-MNCs into iNCs using the same SeV strategy. For this purpose, 250,000 MNCs $(\mathrm{n}=4)$ were infected at high MOI (ten and five for SOX2 and c-MYC, respectively) and cocultured on irradiated rat astrocytes in the presence of $\mathrm{N} 2$ medium with BMP, TGF- $\beta$, and GSK-3 $\beta$ inhibitors (Figure $4 \mathrm{~A}$ ). As shown in Figure $4 \mathrm{~B}$, morphological changes in PB-MNCs were similar to those observed in CD133-positive CB cells. Immunostaining showed that within 15 days of induction, PB-iNCs stained for DCX (Figure 4Ca). However, the conversion process was slower and less efficient, and the resulting iNCs showed a lower expansion capacity. In fact PB-iNCs could not be maintained in culture for more than six passages, and only a few cells within the culture were positive for Ki67 (Figure 4Cb). By day 30, PB-iNCs acquired a more mature morphology and expressed markers indicating neuronal commitment (including TUJ1, MAP2, and NF), as indicated by immunostaining and qRT-PCR analysis (Figures 4Cc-e and $4 \mathrm{D}$ ). After 30 days of induction, about $16 \%$ (n[cells] = 252 ) of the cells were positive for TUJ1, and $9 \%$ (n[cells] = 158) were positive for MAP2.

As described for CB-iNCs, PB-iNCs were also transduced with SYN::GFP reporter lentivirus and cocultured on irradiated rat astrocytes during 6-8 weeks for neuronal differentiation and whole-cell recordings (Figure 4E). These PB-iNCs displayed inward $\mathrm{Na}^{+}$and outward $\mathrm{K}+$ voltage-dependent currents $(\mathrm{n}=15)$ (Figure $4 \mathrm{~F})$ and were able to fire single and multiple action potentials following injection of depolarizing current steps $(n=7)$ (Figure $4 G)$. However, they did not show spontaneous activity or response to glutamate application $(\mathrm{n}=4)$ (Figure $4 \mathrm{H})$. Intrinsic electrophysiolog- ical properties such as membrane capacitance $(23.29 \pm$ $2.9 \mathrm{pF})$ and resting membrane potential $(-29.0 \pm 4.0 \mathrm{mV})$, but not membrane resistance $(1,174 \pm 156 \mathrm{M} \Omega)$, were significantly different from those recorded in spontaneously active CB-iNCs (see Figure 3D).

Recently, it has been demonstrated that upregulation of $p 16^{I n k 4 a}$ and $p 19^{A r f}$ induces cellular senescence in adult cells that may represent a roadblock for the direct conversion of human fibroblasts into functional neurons (Sun et al., 2014). In line with these findings, we observed that $p 16^{I n k 4 a}$ and $p 19^{A r f}$ mRNA levels were significantly higher in PB-MNCs than in CD133-positive CB cells (Figure S4A). Conversely, telomerase reverse transcriptase (hTERT), which prevents cellular senescence, was higher in CD133-positive CB cells than in PB-MNCs (Figure S4B). These data are in agreement with the hypothesis that regulation of senescence might represent a key step in the direct conversion of somatic cells into neurons and raise the possibility that $p 16^{I n k 4 a}$ and $p 19^{A r f}$ can be targeted to improve neural reprogramming of PB-MNCs in future studies.

\section{DISCUSSION}

Direct reprogramming of human somatic cells into functional neurons has been proposed as an alternative strategy to obtain patient-specific neurons for disease modeling, drug screening, and toxicity tests (Qiang et al., 2014). Indeed, this approach offers some advantages as compared with classic reprogramming to hiPSCs and redifferentiation, notably in time and experimental variability. However, available protocols for generating expandable neural populations rely on the use of mouse cells and do not support the generation of human neurons on a large scale (Cheng et al., 2014; Han et al., 2012; Lujan et al., 2012; Ring et al., 2012; Thier et al., 2012). In the present study, we report a rapid and efficient approach to obtain iNCs from human hematopoietic cells using SeV. Compared with retroviral and lentiviral-based approach, $\mathrm{SeV}$ is more efficient for gene delivery to hematopoietic cells and has been used to generate blood-derived, integration-free hiPSCs (Ban et al., 2011). Here, we successfully obtained iNCs from CD133-positive CB cells in less than 1 week by coexpression of $S O X 2$ and $c-M Y C \mathrm{SeV}$. The highly proliferative nature of CD133-positive $\mathrm{CB}$ cells during the first week of the reprogramming process made difficult to accurately determine the efficiency of CB-iNCs. Nevertheless, the yield of CB-iNCs was really remarkable as infection of 50,000 CD133-positive CB cells resulted in over 20 million of N-CAM-positive cells 2 weeks later. Moreover, CB-iNCs could be cryopreserved, propagated, and further expanded for $>60$ passages without losing their functional properties. Upon differentiation, 


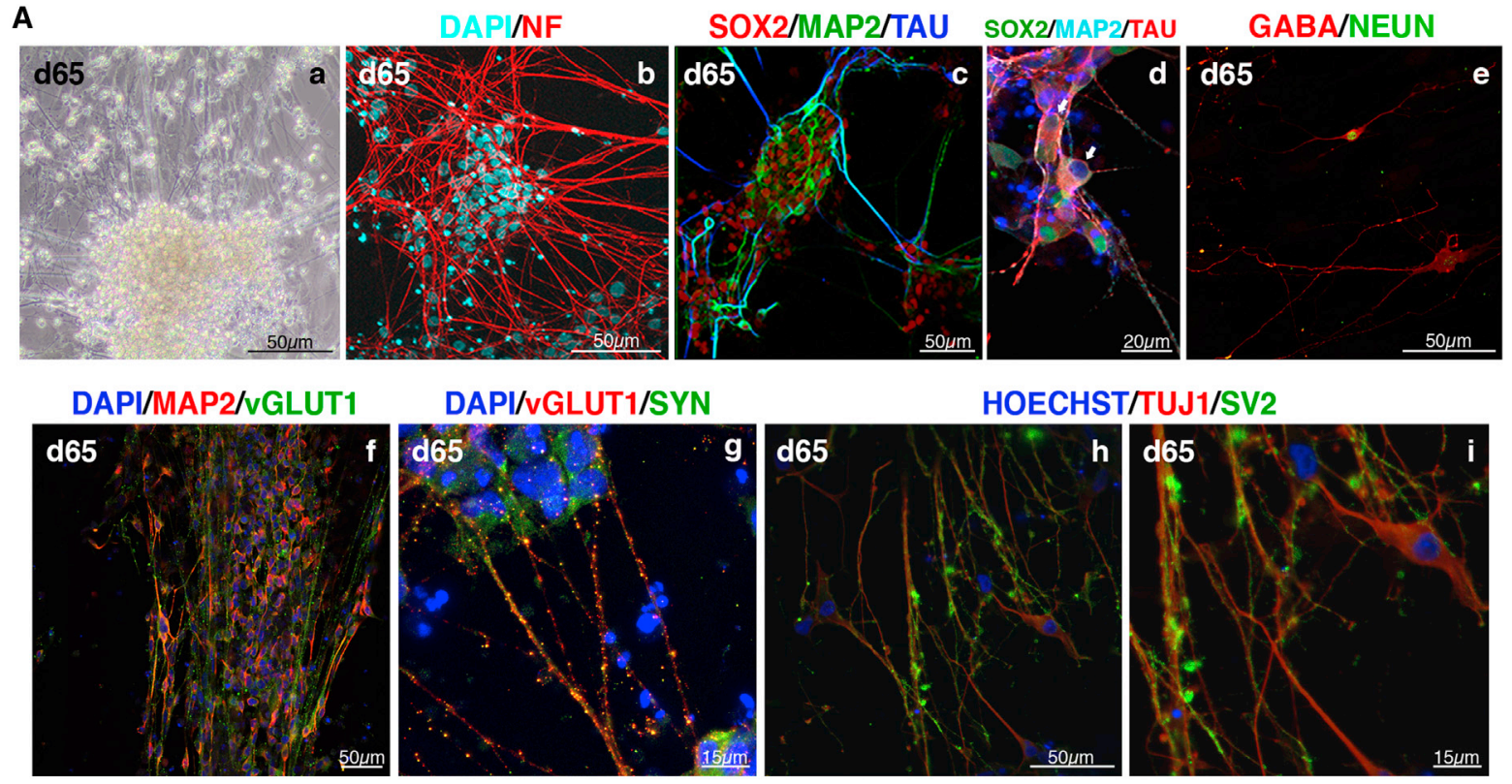

B

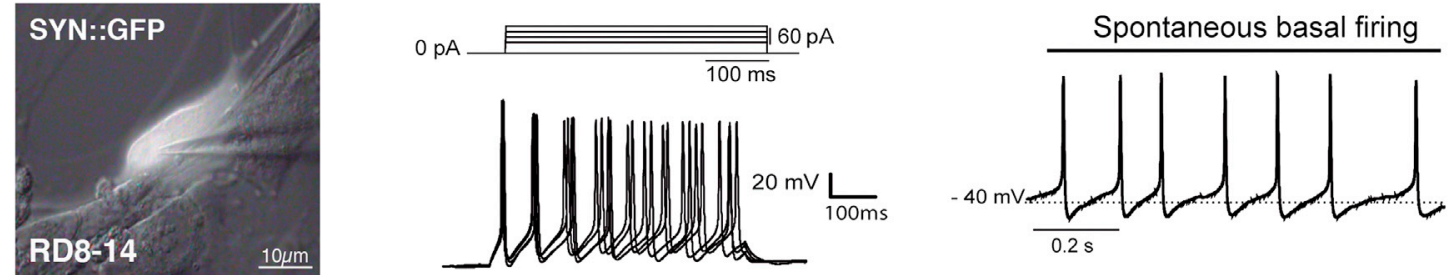

C
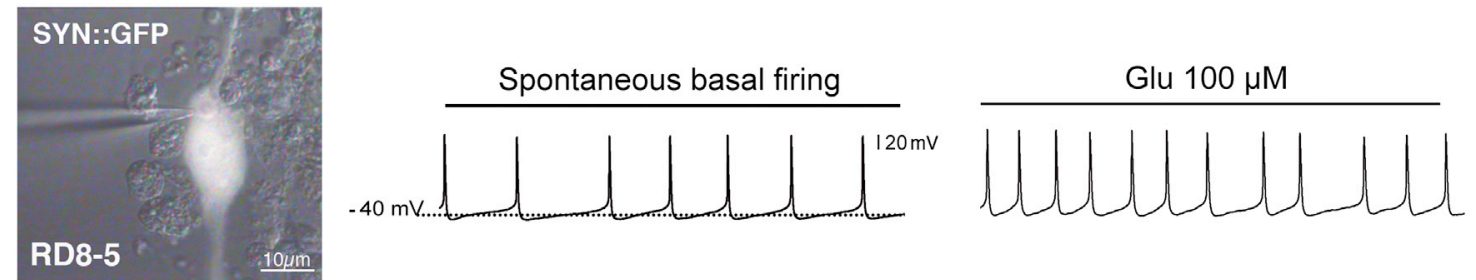

RD8-5
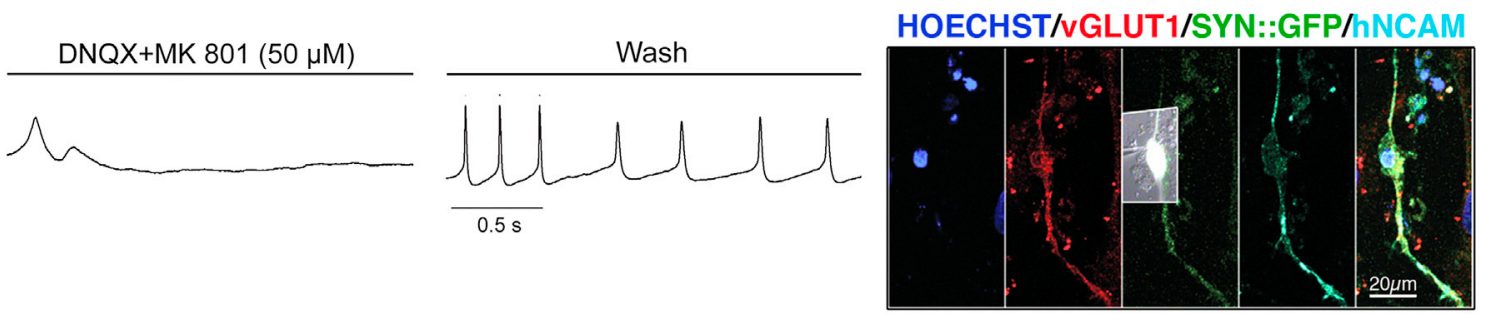

D
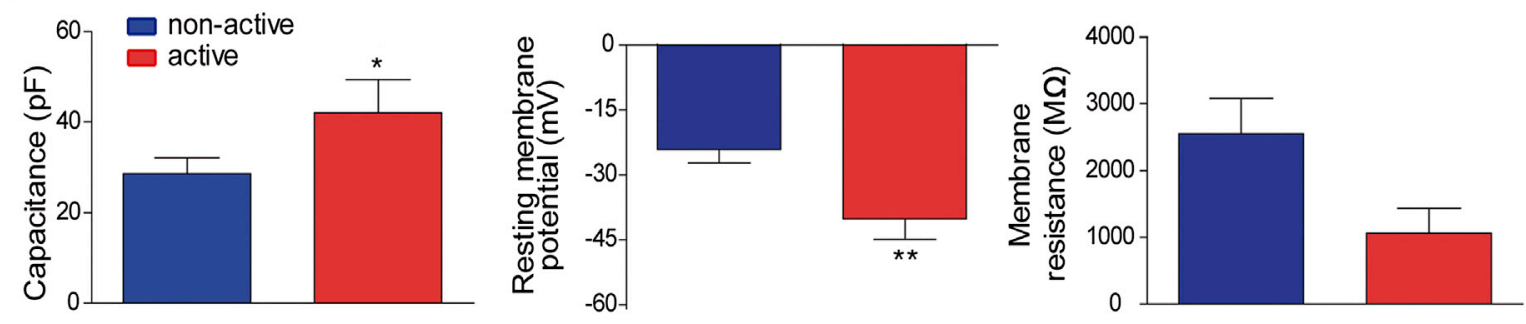
CB-iNCs expressed typical mature neuronal markers, such as MAP2, TAU, and NEUN, and displayed electrophysiological properties including spontaneous action potentials and modulation of their activity by glutamate and GABA neurotransmitters.

Transient expression of the four Yamanaka factors has been used as alternative approach to generate iNPCs (Kim et al., 2011; Lu et al., 2013; Thier et al., 2012). However, the presence of pluripotent intermediate cell types could not be excluded in those studies and the protocols were laborious and time consuming. In this regard, our study represents a technical advance for the fast and efficient generation of human integration-free iNCs, without forcing the cells to first go back to an intermediate pluripotent stage (Mitchell et al., 2014). Noteworthy, iNPCs have been recently obtained from mouse fibroblasts using small molecules under hypoxia conditions without exogenous transcription factors (Cheng et al., 2014). While these data represent a safe and attractive strategy for the generation of neural progenitors, the effectiveness of this approach on human cells is still unclear. It would be interesting to assay whether this approach allows lineage conversion of human hematopoietic cells.

Direct neural conversion from different cell types has been achieved using the proneurogenic factor ASCL1/ MASH1 (Caiazzo et al., 2011; Karow et al., 2012; Marro et al., 2011; Pang et al., 2011; Vierbuchen et al., 2010; Wapinski et al., 2013), where it collaborates with BRN2, MYTL1, and SOX2. Most recently, Wernig's group demonstrated that MASH1 alone is sufficient to convert fibroblasts into iNCs, suggesting that MASH1 is the most important transcription factor for neural conversion (Chanda et al., 2014). Intriguingly, we did not observe activation of
MASH1, suggesting that $S O X 2$ activates the neural program either downstream or independently of MASH1. SOX2 is expressed during development in self-renewing and multipotent neuroepithelial stem cells (Avilion et al., 2003; Ferri et al., 2004). SOX2 maintains neural progenitor identity and inhibits neuronal differentiation (Bylund et al., 2003; Graham et al., 2003). Moreover, in several organs, SOX2positive cells display self-renewal and maintain tissue homeostasis (Arnold et al., 2011). Of note, Cheng et al. (2014) showed that conversion of mouse fibroblasts into neural progenitors by inhibition of histone deacetylase inhibitors, TGF- $\beta$, and GSK- $3 \beta$ is accompanied by the activation of endogenous SOX2 expression. Accordingly, we observed high and sustained levels of endogenous SOX2 from day 10 of induction and the expression of SOX2 was maintained during propagation of CB-iNCs. These data are in line with previous works showing that forced expression of SOX2 alone or in combination with other transcription factors can convert mouse and human fibroblasts into neural stem cells (Ring et al., 2012) or multipotent neural progenitors (Lujan et al., 2012). Noteworthy, SOX2 and BRN2 have been recently used to convert fibroblasts into NPCs (Lujan et al., 2012; Zou et al., 2014). Furthermore, SOX2 has been shown to co-occupy with BRN2 (a POU factor) a large set of distal enhancers in NPCs and regulate together a subset of genes important for neural fate (Lodato et al., 2013; Miyagi et al., 2006). Consistent with these data we observed the induction of endogenous BRN2 in our CB-iNCs during the conversion process. Based on these findings, it is tempting to speculate that SOX2 with $c-M Y C$ initiate the neural conversion of blood cells and then SOX2 and BRN2 cooperate to drive the CB-iNCs toward neuronal linages.

Figure 3. In Vitro Neuronal Differentiation and Whole-Cell Patch-Clamp Recordings of CB-iNCs

(A) Representative phase contrast (a) and immunofluorescence (b-i) images of CB-iNCs at differentiation day 65 . Differentiated CB-iNCs expressed postmitotic mature markers such as axonal specific neurofilament SMI 312 (NF), MAP2, TAU (T46 epitope), and NEUN (RBF0X3) (b-e). (d) High-magnification image of TAU-positive cells showing downregulation of SOX2 nuclear staining, indicated by white arrows. CB-iNCs can differentiate into inhibitory GABA-positive neurons (e) and excitatory vGLUT1-positive neurons ( $f$ ). Mature neurons derived from CB-iNCs after 65 days of differentiation expressed synaptic proteins, such as SYN and SV2 ( $g-i)$. Scale bars are as indicated in the panels.

(B) Current-clamp recordings from a GFP-positive (SYN::GFP) cell showing evoked action potentials by injecting 20 pA current steps (middle panel) and spontaneous action potentials at a $-40 \mathrm{mV}$ resting membrane potential $(\mathrm{I}=0)$ (right panel). The scale bar is as indicated in the panel.

(C) Current-clamp recordings of another GFP-positive (SYN::GFP) cell in the same culture showing spontaneous activity that was pharmacologically modulated by glutamate (upper right panel) and glutamate antagonists (DNQX: non-NMDA receptor antagonist, MK801: NMDA receptor antagonist, left and middle bottom panels). Representative traces of spontaneous activity are truncated for clarity. Immunofluorescence confirmed expression of vGLUT1, together with GFP (SYN::GFP) and human specific N-CAM in this cell (right bottom panel). Scale bars are as indicated in the panels.

(D) Spontaneously active cells showed more mature electrophysiological properties, as capacitance was significantly higher $\left(t_{35}=1.66\right.$, $p=0.05$ ) (left panel) and the resting membrane potential significantly lower $\left(t_{29}=2.51, p<0.01\right)$ (middle panel) than those recorded from nonactive cells. Membrane resistance was smaller, although not statistically different $\left(t_{35}=1.45, p=0.07\right)\left(\right.$ right panel). ${ }^{*} p \leq 0.05$; ${ }^{* *} \mathrm{p}<0.01$; unpaired t test.

See also Figure S3. 
A

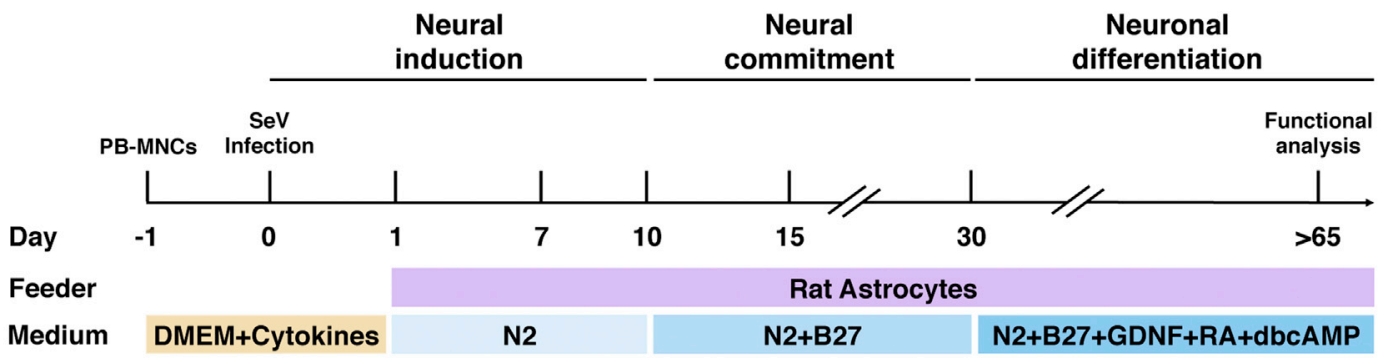

B

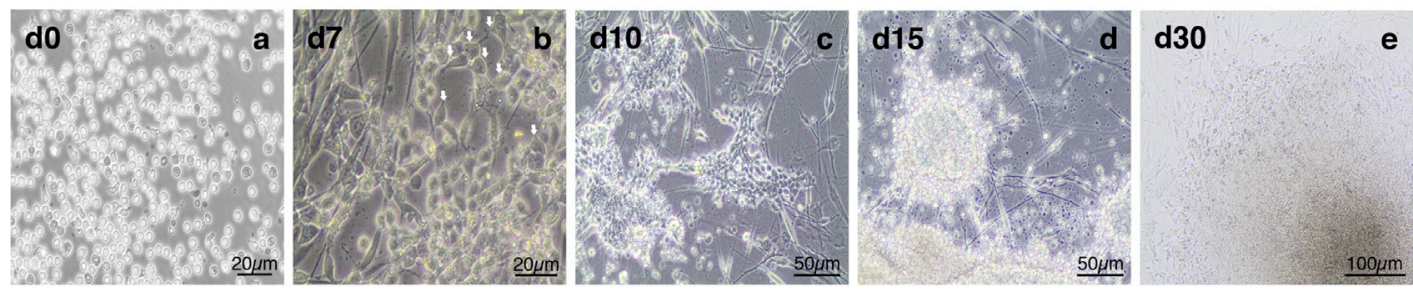

C HUNU/DCX

DAPI/Ki67

DAPI/TUJ1/NF DAPI/TUJ1/NF

DAPI/MAP2
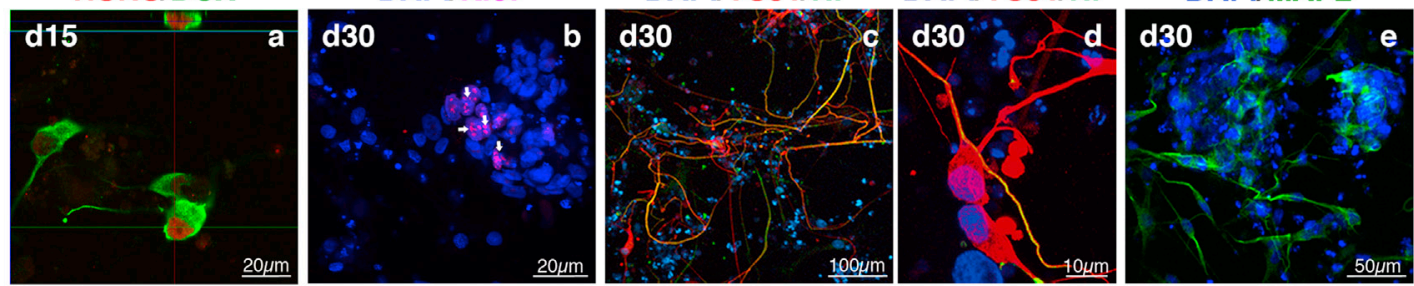

D

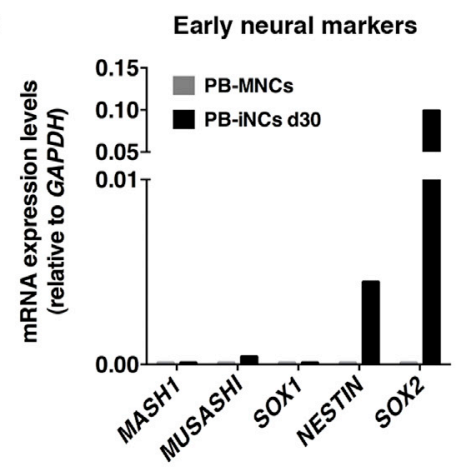

E

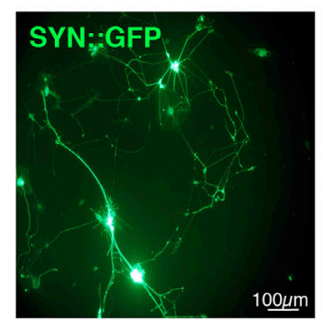

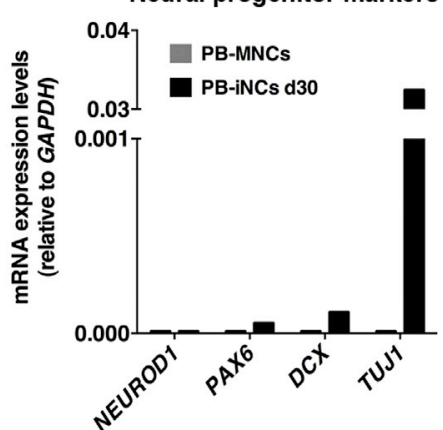
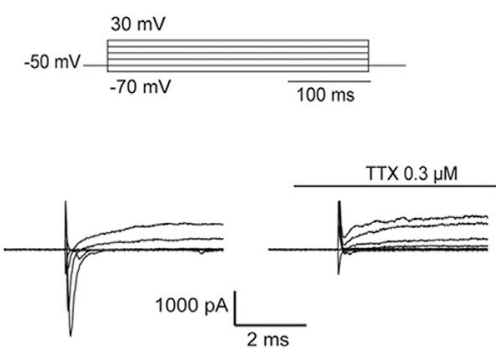

Mature neuronal markers

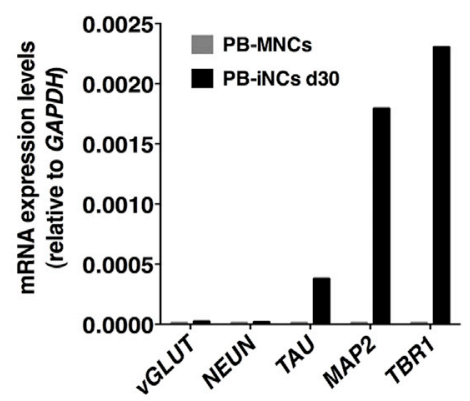

G
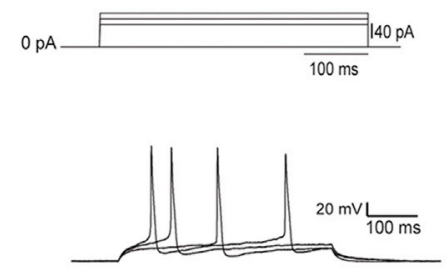

H Glu $200 \mu \mathrm{M} \quad$ DNQX $50 \mu \mathrm{M}$ 
Based on their in vitro characteristics and gene expression profile, it is plausible that CB-iNCs contain an amplifying neural population that can be expanded under chemically defined conditions and primed to differentiate into more committed progenitors. This population presents similarities with the SOX2-positive cells present in the neurogenic niches of the adult mammalian brain like the $\mathrm{Nestin}^{+/-} / \mathrm{SOX2}^{+} / \mathrm{GFAP}^{-}$in the adult hippocampus and in the subventricular zone (Codega et al., 2014; Encinas et al., 2011). These findings are in agreement with our previous work and confirm that the coexpression of SOX2 and c-MYC in CD133-positive CB cells induces direct conversion to neuronal cells at different stages of specification and maturation (Giorgetti et al., 2012). Interestingly, $c-M Y C$, known to increase the reprogramming efficiency in many systems, has been recently reported to function as a proneurogenic factor during development promoting neurogenic cell division (Zinin et al., 2014).

CD133-positive CB cells were easier to reprogram than PB-MNCs. This was not surprising because CD133-positive CB cells are young cells expected to carry minimal somatic mutations, are enriched in highly proliferative primitive hematopoietic stem/progenitor cells, possess the immunological immaturity of newborn cells, and have been previously shown to have a broad differentiation capacity (Harris, 2009; Kögler et al., 2004; Rocha et al., 2004). Interestingly, a recent epigenetic study revealed complete unmethylation status of promoter/enhancer regions of SOX2, among other pluripotent genes, in CB stem cells (Santourlidis et al., 2011). In addition, in some cases, the SOX2 promoter was found to display the bivalent histone modification typical of pluripotent stem cells (Santourlidis et al., 2011), suggesting a permissive chromatin organization in CB stem cells. In contrast, PB-MNCs are composed of committed and terminally differentiated cells and are devoid of stem/progenitor hematopoietic cells. Furthermore, they comprise noncycling, mature immune cells, which have already undergone complex genetic rearrangements such as T cell and B cell receptor rearrangements (Zhang, 2013). Thus, our data provide additional evidence that the cellular context, the cellular ontogeny and very likely the epigenetic status of the target cells have an impact on the outcome of the conversion process (Ladewig et al., 2013). The generation of expandable neuronal populations from PB cells would be an important step forward in the production of patient-specific iNCs for disease modeling and drug screening interventions. It would be fascinating to determine whether inhibition of $p 16^{I n k 4}$ / $p 19^{A r f}$ or overexpression of $h T E R T$ in PB-MNCs improves their conversion into neuronal cells. In parallel, further studies should aim to elucidate the relative contribution of the exogenous factor combination and the cellular context determined by the origin and the nature of target cells.

Finally, there has been recently some concern about $\mathrm{SeV}$ elimination (Yoshioka et al., 2013).

Although our established iNCs rapidly eliminated much of the $\mathrm{SeV}$, low $\mathrm{SeV}$ expression persisted over time as detected by qRT-PCR. The reason for this is unclear and possibly involves RNA binding proteins (Iacoangeli and Tiedge, 2013; Narayanan and Makino, 2013; Scheller and Díez, 2009). Nevertheless, in this study, we used a

Figure 4. Generation and Characterization of iNCs from PB-MNCs Using SeV

(A) Schematic representation of neural induction of PB-MNCs. Two hundred fifty thousand PB-MNCs were transduced with SOX2 and c-MYC $\mathrm{SeV}$ vectors at high MOI. At day 1, infected cells were plated on irradiated rat astrocytes in the presence of N2 medium supplemented with LDN, CHIR99021, and SB431542 compounds. From days 10 to 30, cells were cultured in N2 + B27 medium. From day 30 onward, PB-iNCs were terminally differentiated in the presence of $\mathrm{N} 2+\mathrm{B} 27$ medium with BDNF, GDNF, RA, and dbcAMP for another 6-8 weeks.

(B) Representative phase contrast images illustrating the time course of the conversion of PB-MNCs into neural cells. Similar to CB, some neuroepithelial cells (indicated by white arrows) emerged as early as day 7 ( $n=4$ independent experiments). Scale bars are as indicated in the panels.

(C) Representative immunofluorescence images of converted PB-iNCs at days 15 and 30. At day 15, PB-iNCs were DCX positive and showed an immature morphology; (a) is a confocal orthogonal reconstruction to ensure colocalization with human nuclear antigen HUNU. There were few Ki67-positive cells (indicated by white arrows) in concordance with the limited expansion capacity (b). By day 30, PB-iNCs displayed a more mature morphology and expressed TUJ1, axonal specific neurofilament (NF), and MAP2 (c-e). Scale bars are as indicated in the panels.

(D) Representative qRT-PCR analysis of early, immature, and mature neuronal markers in PB-MNCs and PB-iNCs after 30 days of neural induction. Note that expression of these genes was not detected in untransduced PB-MNCs.

(E) PB-iNCs in culture expressing SYN::GFP after lentiviral transduction. GFP-positive cells were patched for electrophysiology. The scale bar is as indicated in the panel.

(F) Inward $\mathrm{Na}^{+}$and outward $\mathrm{K}^{+}$voltage-dependent currents triggered upon $-70 \mathrm{mV}$ to $+50 \mathrm{mV}$ voltage steps $\left(\mathrm{V}_{\mathrm{h}}=-50 \mathrm{mV}\right)$. $\mathrm{Na}^{+}$currents were TTX sensitive. Representative traces of voltage-dependent currents were truncated and expanded for clarity.

(G) PB-iNCs GFP-positive cells showed action potentials evoked by somatic current injection (step $20 \mathrm{pA}, \mathrm{n}=15$ ).

(H) No current changes were observed in response to either glutamate or the glutamate receptor antagonist DNQX $\left(V_{h}=-50 \mathrm{mV}\right)$.

See also Figure S4. 
temperature-sensitive vector that could be eliminated upon temperature treatment at $39^{\circ} \mathrm{C}$.

In conclusion, we demonstrate a fast and efficient generation of iNCs from CD133-positive CB cells using nonintegrative SeV. These CB-iNCs are highly expandable and can be differentiated under defined culture conditions into neurons electrophysiologically competent. The short time course and high reproducibility of our approach open new avenues for drug screening and toxicity studies. Our study also underscores the impact of the target cell nature on conversion efficiency.

\section{EXPERIMENTAL PROCEDURES}

\section{Generation of iNCs from Human Blood Cells}

Umbilical CB units $(n=5)$ were obtained from Hospital Donostia upon signed informed consent. The project was approved by the Institutional Review Board of Hospital Donostia. Within $24 \mathrm{hr}$ of $\mathrm{CB}$ collection, CD133-positive cells were isolated as previously described (Giorgetti et al., 2009); 50,000 CD133-positive cells were infected with SeV (Life Technologies) encoding the two transcription factors SOX2 and $c-M Y C$ (MOI $=3$ and $\mathrm{MOI}=1.5$ respectively). At $24 \mathrm{hr}$ after infection (day 1), fresh CB culture medium was added. On day 2, infected CD133-positive CB cells were plated onto primary rat irradiated astrocytes (Lonza) in neural induction medium ([N2 (1X) Invitrogen], LDN [500 ng/ml; PeproTech], CHIR [3 $\mu \mathrm{M}$; Cayman Chemical], SB-431542 [10 $\mu \mathrm{M}$; Tocris], and FGF2 [20 ng/ml; Invitrogen]). To estimate the efficiency of the infection, $\sim 10,000$ infected CD133-positive CB cells were used for cytospin centrifugation and anti-Sendai staining (Anti-SeV 1:500; MBL International Corporation) (Table S1). On day 15, cultures containing CB-iNCs were dissociated with acutase in presence of $5 \mu \mathrm{M}$ ROCK inhibitor (Y-27632; Tocris) and reseeded on irradiated rat astrocytes in the presence of neural expansion medium, including N2 (1X), B27 (0.5X), BDNF (20 ng/ml; Peprotech), and FGF2 $(20 \mathrm{ng} / \mathrm{ml})$. At day 30, CB-iNCs were dissociated and reseeded as single cells on rat astrocytes and cultured in Neurobasal media containing $\mathrm{N} 2(1 \mathrm{X})$ and $\mathrm{B} 27(1 \mathrm{X})$ supplements, $2 \mathrm{mM}$ L-glutamine, $20 \mathrm{ng} / \mathrm{ml} \mathrm{BDNF}, 20 \mathrm{ng} / \mathrm{ml}$ glial cell-derived neurotrophic factor (GDNF), $200 \mu \mathrm{M}$ ascorbic acid, $0.5 \mathrm{mM}$ dibutyryl cAMP (dbcAMP; Sigma-Aldrich), and retinoic acid (RA) $20 \mu \mathrm{g} / \mathrm{ml}$ (Sigma-Aldrich). PB was obtained from healthy volunteers (35-40 years old) upon informed consent. PB-MNCs were enriched by density gradient centrifugation, and 250,000 PB-MNCs $(\mathrm{n}=4)$ were infected by SOX2 and c-MYC SeV (10 and $5 \mathrm{MOI}$, respectively). At $24 \mathrm{hr}$ after infection, viral medium was removed, and infected cells were transferred on rat astrocytes in neural induction medium as described above. Infection efficiency and culture in neural induction medium was performed as for CD133-positive CB cells.

\section{RNA Purification and qRT-PCR}

Isolation of total RNA was performed using either RNeasy Mini Kit (QIAGEN) or RNAqueous-Micro kit (Ambion) based on the cell number available; $1 \mu \mathrm{g}$ of RNA was used to synthesize cDNA using the SuperScript III Reverse Transcriptase kit (Invitrogen). qPCR was done using SybrGreen or IDT primetime qPCR assay. Primer sequences and probes used are described in Table S2 and in the Supplemental Experimental Procedures.

\section{Immunofluorescence Analysis}

Cells were analyzed by immunofluorescence staining as previously described (Sanchez-Pernaute et al., 2008). Cells cultured on coverslips were fixed with $4 \%$ paraformaldehyde. Cells were incubated in blocking buffer: $1 \times$ PBS with $10 \%$ normal donkey serum and permeabilized with $0.1 \%$ Triton X-100 for $1 \mathrm{hr}$ at room temperature. Stained cells were examined using an LSM510 Meta confocal microscope equipped with ultraviolet, argon, and helium-neon lasers (Carl Zeiss) and analyzed using Image J (NIH). Antibodies and quantification methods used are described in Table S1 and Supplemental Experimental Procedures.

\section{Electrophysiology}

For identification of induced neurons, cells were transduced with a lentivirus expressing GFP under the control of the synapsin promoter (SYN::GFP, kindly provided by Dr. Atsushi Miyanohara [UCSD]) according to previously published protocols (Pruszak et al., 2007). Glass coverslips were transferred to a recording chamber and perfused with artificial cerebral spinal fluid (aCSF) solution containing (in mM) $125 \mathrm{NaCl}, 2.5 \mathrm{KCl}, 1.2 \mathrm{MgCl}_{2}, 26 \mathrm{NaH}_{2} \mathrm{CO}_{3}$, $1.25 \mathrm{NaH}_{2} \mathrm{PO}_{4}, 2.4 \mathrm{CaCl}_{2}, 11$ D-glucose saturated with $95 \% \mathrm{O}_{2}$, and $5 \% \mathrm{CO}_{2}$ (pH 7.3-7.4, 295-300 mOsm). Neurons were identified as large green fluorescent cells using a Nikon Eklipse FN-1 fluorescent microscope. Whole-cell recordings were made at room temperature using glass pipettes (4-7 M $)$ ) pulled with a PC-10 puller (Narishige) and filled with an internal solution containing (in mM) 130 potassium gluconate, $5 \mathrm{NaCl}, 1 \mathrm{MgCl}_{2}, 1 \mathrm{EDTA}, 10$ HEPES, 2 Mg-ATP, 0.5 Na-GTP, and 10 phosphocreatine (290-295 mOsm). To record whole-cell currents, experiments were carried out in voltage-clamp mode holding the membrane potential at $-50 \mathrm{mV}\left(\mathrm{V}_{\mathrm{h}}=-50 \mathrm{mV}\right)$. Voltage-dependent currents were triggered by depolarizing the membrane potential from -70 to $+50 \mathrm{mV}(300 \mathrm{~ms})$. Spontaneous and evoked action potentials, induced by injecting current steps from 0 to $+120 \mathrm{pA}(500 \mathrm{~ms})$, were recorded in current-clamp mode. Recordings were detected with a Multiclamp-700B amplifier, filtered at $5 \mathrm{kHz}$, and digitized with a Digidata 1440 (Molecular Devices). Data were sampled at $10 \mathrm{kHz}$ with Clampex 10.2 software (Molecular Devices). Tetrodotoxin (TTX) (Sigma-Aldrich), glutamate (Research Biochemicals International), GABA (Abcam Biochemicals) and glutamate antagonists MK801, and DNQX (Tocris) were diluted in aCSF and perfused onto the cultures by gravity flow $(1.5-2.0 \mathrm{ml} / \mathrm{min})$.

\section{SUPPLEMENTAL INFORMATION}

Supplemental Information includes Supplemental Experimental Procedures, four figures, and two tables and can be found with this article online at http://dx.doi.org/10.1016/j.stemcr. 2014.10.008.

\section{AUTHOR CONTRIBUTIONS}

J.C. performed experiments, data analysis, and manuscript writing. P.M. performed data interpretation and manuscript writing. C.B.-C. performed experiments, data analysis, and 
interpretation. M.S., A.S., L.Z., N.V., and A.Z. performed experiments. J.M.C. performed data interpretation, K.-C.S. virus production, and L.U. data analysis and interpretation. X.C.-V. performed reprogramming experiments and analysis. M.T. performed experiments and contributed to experimental design, data analysis and interpretation, and manuscript writing. R.S.-P. performed experimental design, data analyses, and interpretation and manuscript writing. A.G. conceived the study and performed experiments, experimental design, data analyses, and interpretation and manuscript writing. All authors approved the last version of the manuscript.

\section{ACKNOWLEDGMENTS}

Funding for this project was provided by the Basque Government, Department of Industry (SAIOTEK PE12IB003), and Kutxa Obra Social to A.G.; the Basque Government, Department of Education (EC2011-47) and Kutxa Obra Social to R.S.-P.; Obra Social "La Caixa-Fundació Josep Carreras," ISCII/ERANET (P112/03112) to P.M.; the Ministerio de Economía y Competitividad (SAF201237417) to J.M.C., Spain; Instituto de Salud Carlos III, Ministerio de Economia y Competitividad (RETICS [RD12/0019/0002; Red de Terapia Celular]) to J.M.C.; and Generalitat de Catalunya (2009SGR-00326); The University of the Basque Country (UFI 11/32) and the Spanish Government; The Ministerio de Economía y Competitividad (FIS PI12/00613) to C.B.-C., L.U., and M.T.; and in part from the National Institute of Neurological Disorders and Stroke R21 NS067335 to K.C.-S. C.B.-C. was supported by a UPV/ EHU fellowship. We would like to thank Drs. Kausalia Vijayaragavan and Marc Bosse for helpful discussion and Angélica Horillo and Clara Bueno for technical assistance. Some antibodies were obtained from the Developmental Studies Hybridoma Bank (DSHB) developed under the auspices of the National Institute of Child Health and Human Development and maintained by the Department of Biology, University of Iowa.

Received: June 17, 2014

Revised: October 14, 2014

Accepted: October 14, 2014

Published: November 13, 2014

\section{REFERENCES}

Ambasudhan, R., Talantova, M., Coleman, R., Yuan, X., Zhu, S., Lipton, S.A., and Ding, S. (2011). Direct reprogramming of adult human fibroblasts to functional neurons under defined conditions. Cell Stem Cell 9, 113-118.

Arnold, K., Sarkar, A., Yram, M.A., Polo, J.M., Bronson, R., Sengupta, S., Seandel, M., Geijsen, N., and Hochedlinger, K. (2011). Sox2(+) adult stem and progenitor cells are important for tissue regeneration and survival of mice. Cell Stem Cell 9, 317-329.

Avilion, A.A., Nicolis, S.K., Pevny, L.H., Perez, L., Vivian, N., and Lovell-Badge, R. (2003). Multipotent cell lineages in early mouse development depend on SOX2 function. Genes Dev. 17, 126-140. Ban, H., Nishishita, N., Fusaki, N., Tabata, T., Saeki, K., Shikamura, M., Takada, N., Inoue, M., Hasegawa, M., Kawamata, S., and Nishikawa, S. (2011). Efficient generation of transgene-free human induced pluripotent stem cells (iPSCs) by temperature-sensitive Sendai virus vectors. Proc. Natl. Acad. Sci. USA 108, 14234-14239.

Bellin, M., Marchetto, M.C., Gage, F.H., and Mummery, C.L. (2012). Induced pluripotent stem cells: the new patient? Nat. Rev. Mol. Cell Biol. 13, 713-726.

Bylund, M., Andersson, E., Novitch, B.G., and Muhr, J. (2003). Vertebrate neurogenesis is counteracted by Sox1-3 activity. Nat. Neurosci. 6, 1162-1168.

Caiazzo, M., Dell'Anno, M.T., Dvoretskova, E., Lazarevic, D., Taverna, S., Leo, D., Sotnikova, T.D., Menegon, A., Roncaglia, P., Colciago, G., et al. (2011). Direct generation of functional dopaminergic neurons from mouse and human fibroblasts. Nature 476, 224-227.

Chanda, S., Ang, C.E., Davila, J., Pak, C., Mall, M., Lee, Q.Y., Ahlenius, H., Jung, S.W., Südhof, T.C., and Wernig, M. (2014). Generation of Induced Neuronal Cells by the Single Reprogramming Factor ASCL1. Stem Cell Rep. 3, 282-296.

Cheng, L., Hu, W., Qiu, B., Zhao, J., Yu, Y., Guan, W., Wang, M., Yang, W., and Pei, G. (2014). Generation of neural progenitor cells by chemical cocktails and hypoxia. Cell Res. 24, 665-679.

Codega, P., Silva-Vargas, V., Paul, A., Maldonado-Soto, A.R., Deleo, A.M., Pastrana, E., and Doetsch, F. (2014). Prospective identification and purification of quiescent adult neural stem cells from their in vivo niche. Neuron $82,545-559$.

Encinas, J.M., Michurina, T.V., Peunova, N., Park, J.H., Tordo, J., Peterson, D.A., Fishell, G., Koulakov, A., and Enikolopov, G. (2011). Division-coupled astrocytic differentiation and age-related depletion of neural stem cells in the adult hippocampus. Cell Stem Cell 8, 566-579.

Ferri, A.L., Cavallaro, M., Braida, D., Di Cristofano, A., Canta, A., Vezzani, A., Ottolenghi, S., Pandolfi, P.P., Sala, M., DeBiasi, S., and Nicolis, S.K. (2004). Sox 2 deficiency causes neurodegeneration and impaired neurogenesis in the adult mouse brain. Development 131, 3805-3819.

Giorgetti, A., Montserrat, N., Aasen, T., Gonzalez, F., RodríguezPizà, I., Vassena, R., Raya, A., Boué, S., Barrero, M.J., Corbella, B.A., et al. (2009). Generation of induced pluripotent stem cells from human cord blood using OCT4 and SOX2. Cell Stem Cell 5, 353-357.

Giorgetti, A., Marchetto, M.C., Li, M., Yu, D., Fazzina, R., Mu, Y., Adamo, A., Paramonov, I., Cardoso, J.C., Monasterio, M.B., et al. (2012). Cord blood-derived neuronal cells by ectopic expression of Sox 2 and c-Myc. Proc. Natl. Acad. Sci. USA 109, 12556-12561.

Graham, V., Khudyakov, J., Ellis, P., and Pevny, L. (2003). SOX2 functions to maintain neural progenitor identity. Neuron 39, 749-765.

Guo, Z., Zhang, L., Wu, Z., Chen, Y., Wang, F., and Chen, G. (2014). In Vivo direct reprogramming of reactive glial cells into functional neurons after brain injury and in an Alzheimer's disease model. Cell Stem Cell 14, 188-202.

Han, D.W., Tapia, N., Hermann, A., Hemmer, K., Höing, S., AraúzoBravo, M.J., Zaehres, H., Wu, G., Frank, S., Moritz, S., et al. (2012). Direct reprogramming of fibroblasts into neural stem cells by defined factors. Cell Stem Cell 10, 465-472. 
Harris, D.T. (2009). Non-haematological uses of cord blood stem cells. Br. J. Haematol. 147, 177-184.

Hu, B.Y., Weick, J.P., Yu, J., Ma, L.X., Zhang, X.Q., Thomson, J.A., and Zhang, S.C. (2010). Neural differentiation of human induced pluripotent stem cells follows developmental principles but with variable potency. Proc. Natl. Acad. Sci. USA 107, 4335-4340.

Iacoangeli, A., and Tiedge, H. (2013). Translational control at the synapse: role of RNA regulators. Trends Biochem. Sci. 38, 47-55.

Johnson, M.A., Weick, J.P., Pearce, R.A., and Zhang, S.C. (2007). Functional neural development from human embryonic stem cells: accelerated synaptic activity via astrocyte coculture. J. Neurosci. 27, 3069-3077.

Karow, M., Sánchez, R., Schichor, C., Masserdotti, G., Ortega, F., Heinrich, C., Gascón, S., Khan, M.A., Lie, D.C., Dellavalle, A., et al. (2012). Reprogramming of pericyte-derived cells of the adult human brain into induced neuronal cells. Cell Stem Cell 11, 471-476.

Kim, J., Efe, J.A., Zhu, S., Talantova, M., Yuan, X., Wang, S., Lipton, S.A., Zhang, K., and Ding, S. (2011). Direct reprogramming of mouse fibroblasts to neural progenitors. Proc. Natl. Acad. Sci. USA 108, 7838-7843.

Kögler, G., Sensken, S., Airey, J.A., Trapp, T., Müschen, M., Feldhahn, N., Liedtke, S., Sorg, R.V., Fischer, J., Rosenbaum, C., et al. (2004). A new human somatic stem cell from placental cord blood with intrinsic pluripotent differentiation potential. J. Exp. Med. 200, 123-135.

Ladewig, J., Mertens, J., Kesavan, J., Doerr, J., Poppe, D., Glaue, F., Herms, S., Wernet, P., Kögler, G., Müller, F.J., et al. (2012). Small molecules enable highly efficient neuronal conversion of human fibroblasts. Nat. Methods 9, 575-578.

Ladewig, J., Koch, P., and Brustle, O. (2013). Leveling Waddington: the emergence of direct programming and the loss of cell fate hierarchies. Nat. Rev. Mol. Cell Biol. 14, 225-236.

Lodato, M.A., Ng, C.W., Wamstad, J.A., Cheng, A.W., Thai, K.K., Fraenkel, E., Jaenisch, R., and Boyer, L.A. (2013). SOX2 co-occupies distal enhancer elements with distinct POU factors in ESCs and NPCs to specify cell state. PLoS Genet. 9, e1003288.

Lu, J., Liu, H., Huang, C.T., Chen, H., Du, Z., Liu, Y., Sherafat, M.A., and Zhang, S.C. (2013). Generation of integration-free and regionspecific neural progenitors from primate fibroblasts. Cell Reports 3 , 1580-1591.

Lujan, E., Chanda, S., Ahlenius, H., Südhof, T.C., and Wernig, M. (2012). Direct conversion of mouse fibroblasts to self-renewing, tripotent neural precursor cells. Proc. Natl. Acad. Sci. USA 109, 25272532.

Marro, S., Pang, Z.P., Yang, N., Tsai, M.C., Qu, K., Chang, H.Y., Südhof, T.C., and Wernig, M. (2011). Direct lineage conversion of terminally differentiated hepatocytes to functional neurons. Cell Stem Cell 9, 374-382.

Mitchell, R., Szabo, E., Shapovalova, Z., Aslostovar, L., Makondo, K., and Bhatia, M. (2014). Molecular evidence for OCT4-induced plasticity in adult human fibroblasts required for direct cell fate conversion to lineage specific progenitors. Stem Cells 32, 21782187.
Miyagi, S., Nishimoto, M., Saito, T., Ninomiya, M., Sawamoto, K., Okano, H., Muramatsu, M., Oguro, H., Iwama, A., and Okuda, A. (2006). The Sox 2 regulatory region 2 functions as a neural stem cell-specific enhancer in the telencephalon. J. Biol. Chem. 281, 13374-13381.

Narayanan, K., and Makino, S. (2013). Interplay between viruses and host mRNA degradation. Biochim. Biophys. Acta 1829, 732-741.

Pang, Z.P., Yang, N., Vierbuchen, T., Ostermeier, A., Fuentes, D.R., Yang, T.Q., Citri, A., Sebastiano, V., Marro, S., Südhof, T.C., and Wernig, M. (2011). Induction of human neuronal cells by defined transcription factors. Nature 476, 220-223.

Pfisterer, U., Kirkeby, A., Torper, O., Wood, J., Nelander, J., Dufour, A., Björklund, A., Lindvall, O., Jakobsson, J., and Parmar, M. (2011). Direct conversion of human fibroblasts to dopaminergic neurons. Proc. Natl. Acad. Sci. USA 108, 10343-10348.

Pruszak, J., Sonntag, K.C., Aung, M.H., Sanchez-Pernaute, R., and Isacson, O. (2007). Markers and methods for cell sorting of human embryonic stem cell-derived neural cell populations. Stem Cells $25,2257-2268$.

Qiang, L., Inoue, K., and Abeliovich, A. (2014). Instant neurons: directed somatic cell reprogramming models of central nervous system disorders. Biol. Psychiatry 75, 945-951.

Ring, K.L., Tong, L.M., Balestra, M.E., Javier, R., Andrews-Zwilling, Y., Li, G., Walker, D., Zhang, W.R., Kreitzer, A.C., and Huang, Y. (2012). Direct reprogramming of mouse and human fibroblasts into multipotent neural stem cells with a single factor. Cell Stem Cell 11, 100-109.

Rocha, V., Labopin, M., Sanz, G., Arcese, W., Schwerdtfeger, R., Bosi, A., Jacobsen, N., Ruutu, T., de Lima, M., Finke, J., et al.; Acute Leukemia Working Party of European Blood and Marrow Transplant Group; Eurocord-Netcord Registry (2004). Transplants of umbilical-cord blood or bone marrow from unrelated donors in adults with acute leukemia. N. Engl. J. Med. 351, 2276-2285.

Sanchez-Pernaute, R., Lee, H., Patterson, M., Reske-Nielsen, C., Yoshizaki, T., Sonntag, K.C., Studer, L., and Isacson, O. (2008). Parthenogenetic dopamine neurons from primate embryonic stem cells restore function in experimental Parkinson's disease. Brain 131, 2127-2139.

Santourlidis, S., Wernet, P., Ghanjati, F., Graffmann, N., Springer, J., Kriegs, C., Zhao, X., Brands, J., Araúzo-Bravo, M.J., Neves, R., et al. (2011). Unrestricted somatic stem cells (USSC) from human umbilical cord blood display uncommitted epigenetic signatures of the major stem cell pluripotency genes. Stem Cell Res. (Amst.) 6, 60-69.

Scheller, N., and Díez, J. (2009). RNA viruses hijack the mRNA decay machinery to multiply. Cell Cycle 8, 4013-4014.

Su, Z., Niu, W., Liu, M.L., Zou, Y., and Zhang, C.L. (2014). In vivo conversion of astrocytes to neurons in the injured adult spinal cord. Nat. Commun. 5, 3338.

Sun, C.K., Zhou, D., Zhang, Z., He, L., Zhang, F., Wang, X., Yuan, J., Chen, Q., Wu, L.G., and Yang, Q. (2014). Senescence impairs direct conversion of human somatic cells to neurons. Nat. Commun. 5, 4112 . 
Thier, M., Wörsdörfer, P., Lakes, Y.B., Gorris, R., Herms, S., Opitz, T., Seiferling, D., Quandel, T., Hoffmann, P., Nöthen, M.M., et al. (2012). Direct conversion of fibroblasts into stably expandable neural stem cells. Cell Stem Cell 10, 473-479.

Torper, O., Pfisterer, U., Wolf, D.A., Pereira, M., Lau, S., Jakobsson, J., Björklund, A., Grealish, S., and Parmar, M. (2013). Generation of induced neurons via direct conversion in vivo. Proc. Natl. Acad. Sci. USA 110, 7038-7043.

Velasco, I., Salazar, P., Giorgetti, A., Ramos-Mejía, V., Castaño, J., Romero-Moya, D., and Menendez, P. (2014). Concise review: generation of neurons from somatic cells of healthy individuals and neurological patients through induced pluripotency or direct conversion. Stem Cells 32, 2811-2817.

Vierbuchen, T., Ostermeier, A., Pang, Z.P., Kokubu, Y., Südhof, T.C., and Wernig, M. (2010). Direct conversion of fibroblasts to functional neurons by defined factors. Nature 463, 1035-1041.

Wapinski, O.L., Vierbuchen, T., Qu, K., Lee, Q.Y., Chanda, S., Fuentes, D.R., Giresi, P.G., Ng, Y.H., Marro, S., Neff, N.F., et al. (2013). Hierarchical mechanisms for direct reprogramming of fibroblasts to neurons. Cell 155, 621-635.
Yoo, A.S., Sun, A.X., Li, L., Shcheglovitov, A., Portmann, T., Li, Y., Lee-Messer, C., Dolmetsch, R.E., Tsien, R.W., and Crabtree, G.R. (2011). MicroRNA-mediated conversion of human fibroblasts to neurons. Nature 476, 228-231.

Yoshioka, N., Gros, E., Li, H.R., Kumar, S., Deacon, D.C., Maron, C., Muotri, A.R., Chi, N.C., Fu, X.D., Yu, B.D., and Dowdy, S.F. (2013). Efficient generation of human iPSCs by a synthetic self-replicative RNA. Cell Stem Cell 13, 246-254.

Zhang, X.B. (2013). Cellular reprogramming of human peripheral blood cells. Genomics Proteomics Bioinformatics 11, 264-274.

Zhang, Y., Pak, C., Han, Y., Ahlenius, H., Zhang, Z., Chanda, S., Marro, S., Patzke, C., Acuna, C., Covy, J., et al. (2013). Rapid single-step induction of functional neurons from human pluripotent stem cells. Neuron 78, 785-798.

Zinin, N., Adameyko, I., Wilhelm, M., Fritz, N., Uhlén, P., Ernfors, P., and Henriksson, M.A. (2014). MYC proteins promote neuronal differentiation by controlling the mode of progenitor cell division. EMBO Rep. 15, 383-391.

Zou, Q., Yan, Q., Zhong, J., Wang, K., Sun, H., Yi, X., and Lai, L. (2014). Direct conversion of human fibroblasts into neuronal restricted progenitors. J. Biol. Chem. 289, 5250-5260. 